\title{
Correction to: MTPA operation scheme with current feedback in V/f control for PMSM drives
}

\author{
Won-Jae Kim ${ }^{1}$ - Sang-Hoon $\mathrm{Kim}^{2}$
}

Published online: 26 October 2020

(c) The Korean Institute of Power Electronics 2020

\section{Correction to: \\ Journal of Power Electronics (2020) 20:524-537 \\ https://doi.org/10.1007/s43236-020-00045-3}

Due to an unfortunate oversight the acknowledgement section has been omitted. It should be read:

\section{Acknowledgements}

This research was conducted with the support of the Korea Energy Technology Evaluation and Planning (Energy Technology Development Project Industrial Technology Innovation Project: Task No. 20183010140980).

The original article can be found online at https://doi.org/10.1007/ s43236-020-00045-3.

Sang-Hoon Kim

kshoon@kangwon.ac.kr

1 Department of Electrical and Medical Convergent

Engineering, Kangwon National University, Chuncheon,

Korea

2 Department of Electrical and Electronics Engineering, Kangwon National University, Chuncheon, Korea 